\title{
1. ANALOGÍA Y TEOLOGÍA EN SANTO TOMÁS DE AQUINO
}

\section{INTRODUCCIÓN}

Santo Tomás de Aquino ha sido un paradigma o modelo de hacer filosofía y teología no solo en la Orden dominicana, sino en toda la Iglesia católica. El núcleo y la clave de su sistema teológico es la analogía, la cual rige la distinción que hace entre Dios y las creaturas, estableciendo que Dios es el único en el que esencia y esse o existencia no se distinguen, sino que se implican mutuamente, mientras que en las creaturas son distintos con distinción real.

Por eso, trataremos aquí de señalar ese núcleo y clave de su modelo filosófico-teológico, el cual sigue iluminando y orientando la labor teológica hoy en día. Brindaremos algunos trazos de su biografía, para ubicarlo en el contexto de su época y cultura, y después pasaremos a delinear la utilización que hace del concepto de analogía, con lo cual elabora una verdadera hermenéutica analógica que pone al servicio de la teología.

\section{VIDA DE SANTO TOMÁS}

El nacimiento de santo Tomás se coloca entre 1224 y 1225, en el castillo de Roccasecca, cercano a Aquino, en Italia (Weisheipl, 1984). Siendo de los hijos más pequeños de una noble familia, fue 
dedicado - como era costumbre- a la vida religiosa. Pronto fue entregado al monasterio de Monte Cassino, con la esperanza de que, andando el tiempo, llegara a ser abad. Federico II, en guerra contra el papa Gregorio IX, sitió la abadía, y Tomás tuvo que dejarla, con lo cual quedó exento de seguir en la orden benedictina.

Continuó sus estudios en la Universidad de Nápoles. Allí se encontró con las doctrinas de Aristóteles y con la Orden dominicana, cosas ambas que después tendría que conjuntar. Entró a la Orden, pero su familia, que seguía esperando un sitio encumbrado para su hijo, trató de impedirlo. Los superiores lo ocultaron en diversos conventos, pero sus hermanos lo encontraron. Fue recluido en los castillos de Monte San Giovanni y de Roccasecca, hasta que, con la ayuda de sus hermanas, pudo escapar. Se reintegró a la Orden y fue enviado a proseguir sus estudios a Colonia, con san Alberto Magno.

Fue ordenado sacerdote, y comenzó a enseñar en París, en 1252, como bachiller bíblico, que era el inicio. En 1254 fue ascendido a bachiller sentenciario, que consistía en explicar la teología de los Santos Padres, cuyas Sentencias había reunido en un libro Pedro Lombardo. En 1256 recibe la licentia docendi o permiso de enseñar, y al poco recibe también el magisterio en teología, que era lo que ahora se llamaría doctorado.

Los maestros seculares tuvieron desconfianza de los maestros regulares (dominicos y franciscanos), y se desató una acerba polémica en la que santo Tomás supo defender los derechos de los religiosos. Después de eso, en 1259, fue llamado como maestro de teología a la curia papal, primero en la ciudad de Anagni y luego en la de Orvieto. En 1265 se le ve organizando los estudios de la Orden, en el convento de Santa Sabina, de Roma. De nuevo es llamado a enseñar a la curia pontificia en 1267, esta vez en la ciudad de Viterbo. En 1269 es llamado a enseñar por segunda ocasión en París, cosa que no era 
usual, a menos de que se tratase de un maestro muy prestigiado, como lo era Tomás por sus clases y escritos (Grabmann, 1946, pp. 69 y ss.; Torrell, 1998, pp. 417 y ss.).

Dado que en 1272 hubo ciertos disturbios en la Universidad de París, Tomás se desplazó a Nápoles, donde organizó el Estudio General de la Orden. En 1273 tuvo una visión muy especial, que le hizo considerar como paja todo lo mucho que ya había escrito. Es llamado al Concilio de Lyon, y se pone en marcha en enero de 1274, aunque iba enfermo. Su enfermedad se agravó en el camino, y hubo de pedir asilo a los cistercienses en el monasterio de Fossanova. Allí murió en marzo de ese año. El papa que lo canonizó dijo que cada uno de sus escritos era un milagro. Se cuenta que una vez, al estar rezando ante un Cristo, este le habló y le dijo: "Has escrito muy bien sobre mí, Tomás; ¿qué quieres como premio?”. A lo que él respondió: "Nada sino a Ti mismo, Señor" (Bene scripsisti de me, Thoma, quid retribuam te? - Nibil nisi te ipsum). Hablaba tan bien de Dios en sus clases y sermones, al igual que en sus escritos, que Cristo mismo le habló a él. No quería otro premio que no fuera solo Dios. También conocemos, fruto de su experiencia profunda de Dios, sus oraciones y cantos o poemas. Es un modelo de la santificación de la inteligencia que trata de hacer la Orden de Predicadores.

Según puede verse, supo santificar sus actividades concretas y sencillas, a veces monótonas, de la vida diaria. Fue un hombre de estudio y docencia, un santo intelectual, que se dedicó a santificar la intelectualidad, en lugar de mancillarla con soberbias, envidias y fatuidades. En esa vida específica supo ser un buen religioso, un hombre espiritual y un verdadero santo. 


\section{EL ANALOGISMO DE SANTO TOMÁS}

Según hemos dicho, el Aquinate posee un modelo y sistema de teología basado en el concepto de la analogía. La analogía es una doctrina que proviene de los pitagóricos, filósofos presocráticos, pasa por Platón y se sintetiza en Aristóteles. Este último fue el gran sistematizador de la analogía (Gambra, 2002, pp. 20 y ss.). Distingue los términos en unívocos, equívocos y análogos. Los unívocos son claros y distintos, iguales para todos sus significados (como "hombre" se aplica de modo idéntico a todos los seres humanos); los equívocos son confusos y oscuros, se aplican de manera distinta a todos sus significados (como "can" se aplica de manera diferente al animal doméstico, al pez y a la constelación que lleva ese nombre), y la analogía está entre unos y otros, que son en parte idénticos y en parte diferentes (como "ente" se aplica de manera en parte igual y en parte diferente a la sustancia y a los accidentes).

Aristóteles recoge la analogía pitagórica, que era la idea de proporción o proporcionalidad, por la que A:B::C:D, con lo cual se aglutinan o concuerdan y armonizan entes que parecen diversos, pero que también tienen semejanzas o coincidencias. Por ejemplo, 18 el instinto es al animal lo que la razón al hombre, e incluso, en sentido metafórico, pues, entendemos la metáfora "el prado ríe" porque hacemos la siguiente proporción: las flores son al prado lo que la risa al hombre. A la analogía pitagórica, de proporcionalidad, añade otra de tipo platónico, jerárquica, en la cual se atribuye un predicado a distintos sujetos siguiendo un orden jerárquico; por eso, hay un analogado principal y analogados secundarios. Por ejemplo, "sano" se aplica principalmente al animal, pero también (de modo derivado) al alimento, al medicamento, al clima, a la orina, etcétera. Aristóteles la llamaba predicación según un principal (pros hen o ad unum), y, como 
versaba sobre la atribución de un predicado a varios sujetos, se llamó analogía de atribución.

Santo Tomás recoge esta doctrina. Utiliza nombres complicados para los distintos tipos de analogía, pero han sido sistematizados por un seguidor suyo de la época del Renacimiento, el cardenal Cayetano, es decir, Tomás de Vio, que fue maestro general de la Orden y después cardenal de Gaeta, en Italia, de donde el apelativo de Cayetano. Él simplifica la doctrina y ofrece un esquema útil (Gambra, 2002, pp. 71 y ss.). Habla de una analogía de desigualdad, la cual se acerca más a la univocidad, y contiene poca diferencia entre los miembros que separa. Su ejemplo es "virtud" o fuerza, la cual puede ser física o espiritual. Pasa a la analogía de atribución, que ya conocemos. Y luego a la analogía de proporcionalidad, que divide en dos: analogía de proporcionalidad propia y analogía de proporcionalidad impropia o metafórica. Esta última, la correspondiente a la metáfora, es la que más se acerca a la equivocidad.

La analogicidad se ve en santo Tomás en que dispone toda su construcción sistemática de la filosofía y la teología que despliega las nociones o elementos que la componen en un orden analógico, tanto de proporción como de atribución. Utiliza, además, tanto el sentido propio como el metafórico de las expresiones. Asimismo, la analogía de atribución tomista se basa en una ontología de la participación del ser de Dios por parte de las creaturas. Por eso, puede usar la analogía también en la idea o el símbolo del hombre como microcosmos, y en el de los dos libros escritos por Dios (la Biblia y el mundo), y de otras formas. Veamos algunas de ellas. 


\section{EL HOMBRE COMO IMAGEN Y MICROCOSMOS}

Basado en esa idea de participación, Tomás ve que todas las creaturas, en cuanto participan de Dios, llevan su impronta, sobre todo, el hombre. Tomás no exalta esa imagen de Dios, de la Trinidad, en las creaturas, como lo hizo san Buenaventura en su Itinerario de la mente hacia Dios, pero recalca mucho la presencia de la imagen de Dios en el hombre. El hombre es imagen de Dios, ícono de Dios. Esto tiene un lugar preponderante en su antropología filosófica y teológica (Beuchot, 2002, vol. I, pp. 279 y ss.).

Pero también tiene un lugar especial la idea del hombre como microcosmos (Fernández Manzanedo, 1979, pp. 62 y ss.). Lo es por semejanza o analogía: "El hombre se llama mundo menor, en cuanto que en él se da una semejanza del mundo mayor" (De veritate, q. 24, a. 5, arg. sed contra). Pero también lo es de modo ontológico, porque es de alguna manera todo: "Y por esto se llama el hombre mundo menor, porque todas las creaturas del mundo se encuentran de algún modo en él” (Sum. Theol., I, q. 91, a. 1). Refleja el orden del cosmos y todo se orienta a él como fin:

El orden del universo es el fin de todas las creaturas. Pero en el hombre hay cierta semejanza del orden del universo, por lo que se le llama mundo menor, ya que todas las naturalezas confluyen en él de algún modo; así pues, parece que él mismo es en cierta manera fin de todas ellas (In II Sent., dist. 1, q. 2, a. 3, 2o. arg. sed contra).

Esto significa que sirven a su utilidad, pero, por lo mismo, él tiene que cuidarlas. $\mathrm{Y}$ es que no se ordenan a un solo hombre, sino a toda la especie humana (Cont. Gent., l. III, c. 112).

Asimismo, dice Tomás que el hombre es de alguna manera todas las cosas y que su alma también lo es, porque es en potencia la 
receptora de todas las formas inteligibles (In III De Anima, lect. 13, n. 790). Y, ya que el alma humana es de algún modo todas las cosas, también lo es el hombre (Girau, 1995, pp. 251 y ss.).

Con ello, el hombre es, para Tomás, un horizonte o confín del universo material y el espiritual: "El hombre es como el horizonte y el confín de la naturaleza espiritual y de la corporal" (In III Sent., prólogo). Es, por ello mismo, el mediador o la mediación de todo lo existente: "Debe notarse que el hombre, según su naturaleza, está constituido como medio entre las creaturas corruptibles y las incorruptibles" (Sum. Theol., I, 98, 1). Vemos aquí cómo el Aquinate sabe conjuntar la analogía con la iconicidad en el hombre como cierto modelo de la creación.

Por eso, el hombre es la clave del retorno de todas las creaturas al Creador. "Así se completa de algún modo toda la obra divina, en cuanto que el hombre, que fue creado al último, vuelve como por un círculo a su primer principio" (Comp. Theol., lib. I, cap. 201). Y es que el hombre tiene inteligencia y amor, con los que puede adherirse a Dios y volver a Él.

\section{LOS DOS LIBROS}

Y también tiene santo Tomás la imagen de los dos libros, el de la naturaleza y el de la Escritura Sagrada: "Estos escritos consisten en dos libros: a saber, en el libro de la creatura y el libro de la Escritura. El primer libro, cuantas creaturas contiene, tantos escritos óptimos tiene, que sin mentira enseñan la verdad" (1880, t. I, pp. 12-13). Son cifras o símbolos.

Con ello, encontramos, en santo Tomás, una idea muy analógica. Así como el hombre es el análogo del mundo, así el mundo o 
la naturaleza es el análogo de Dios, puesto que incluye al hombre, y, de esta manera, estudiando las creaturas, él se verá elevado a la contemplación del Creador.

\section{DESPLIEGUE DE LA ANALOGÍA}

La doctrina de la analogía, que tanto usa el Aquinate para el conocimiento de Dios y del orden del ser, tiene su raíz en la teoría de la participación. En efecto, solo porque las cosas llevan la participación de Dios, es decir, porque son imágenes suyas, pueden conducir a Él, sobre todo, el hombre. Solo porque los entes tienen la participación del ser, puede haber una analogía de las creaturas con el Creador, y una imagen de Dios en ellas, en especial, en el hombre.

También, por ello, puede el hombre ser el análogo de todo lo existente, en su calidad y condición de microcosmos. Por consiguiente, es el mediador de todo, el horizonte y el confín en el que se cruzan lo espiritual y lo material, lo eterno y lo temporal, lo infinito y lo finito. Gracias a esa analogicidad, la naturaleza puede ser vista como un libro, el libro de las creaturas, que refleja a Dios y conduce a Él (y, otra vez, sobre todo, el hombre, que está contenido en la naturaleza).

Es, pues, un lenguaje muy analógico el que encontramos en Tomás. Pero lo es porque tiene detrás una ontología analógica, basada en la participación, en el ejemplarismo, en la teoría de la imagen o iconicidad: el hombre como ícono de Dios, la naturaleza como ícono del Creador, libro, espejo, etcétera. Todo ello nos habla de una filosofía analógica, o basada en la semejanza, que encontramos en el Aquinate. 
También se ha visto la dialectización de la analogía en santo Tomás (Gómez Caffarena, 1960, pp. 143 y ss.; Scannone, 2005, p. 155). Proviene del Pseudo-Dionisio, es la dialéctica neoplatónica que Tomás agregó a su aristotelismo. Hay en la analogía un momento de afirmación, otro de negación y otro de supereminencia. Y con eso, se da una analogía dialectizada, o una analogía dialéctica, dinámica y no estática.

Por así decir, santo Tomás fue el campeón de la analogía. La analogía o proporción, tanto en su vertiente de proporcionalidad como en la de atribución (llamadas así por su seguidor renacentista el cardenal Cayetano), le sirvieron para captar el orden del universo. Así detectó, por su cuenta, la famosa analogía universal o cósmica, de la que hablaron los estoicos. Además, recibió una analogía dinámica, dialectizada, por su estudio del Pseudo-Dionisio, que ponía en la analogía un momento afirmativo, otro negativo y otro de supereminencia, en el cual se cumplía la dialectización. Y eso lo hereda Tomás, con la ventaja de que esta dialéctica no es como la hegeliana, que se cierra y concluye, en una síntesis que reasume y supera a los contrarios que reunía. No, aquí se trata de una dialéctica abierta, que no concluye perfectamente, sino que permanece en la tensión, que preserva el carácter antitético de los opuestos a los que pone en contacto, y que prefiere aprovechar ese conflicto, y hace que convivan e incluso que trabajen el uno para el otro.

\section{HACIA UNA HERMENÉUTICA ANALÓGICA}

La utilización de la analogía que hace santo Tomás nos mueve a edificar una hermenéutica analógica. La teología se ha vuelto eminentemente hermenéutica, y también, en la tradición tomista, ha de ser analógica. Requiere, pues, de una hermenéutica analógica, la cual 
evite la polarización de una hermenéutica unívoca, demasiado estrecha y cerrada, y una hermenéutica equívoca, demasiado amplia y abierta. La primera nos hará pretender una teología demasiado positivista, y la segunda nos hará incurrir en el relativismo excesivo de las teologías posmodernas. Por eso, se requiere un punto intermedio, de equilibrio prudencial.

Y es que, en verdad, una hermenéutica analógica podrá darnos una teología que transite por los cauces del equilibrio proporcional, con un sentido de la armonía y el orden que da la analogía. Tendrá sus partes entreveradas, como elementos de un todo orgánico, que se despliegue de manera ordenada por todos los resquicios de la teología. Nos dará una teología analógica, como la del Aquinate, con una capacidad de equilibrio proporcional del sentido literal y el sentido alegórico.

Será una teología atenta al símbolo, al simbolismo, o a la simbolicidad o carácter simbólico de los elementos mismos de la religión. El símbolo requiere de la analogía para ser interpretado, para brindar su riqueza. De esta manera, una hermenéutica analógica nos dará una teología viva. Al mismo tiempo bien cimentada, sin perder su carácter sustancial o esencialista, pero tampoco su carácter relacional o existencialista, sino llegando a una unión de ambos aspectos en una síntesis dinámica.

\section{CONCLUSIÓN}

Puede decirse que santo Tomás de Aquino fue el genio de la analogía. Utilizó esta noción para elaborar todo su sistema. Esto le dio una gran mesura, equilibrio o proporción en sus doctrinas. También una notable armonía y orden. 
Además, el Aquinate es un paradigma de nuestra teología dominicana, seguramente el principal, y el que la Iglesia católica ha adoptado como el gran modelo de su quehacer teológico. Por eso, lo ha recomendado tanto a lo largo de los siglos. También hoy tiene mucho que decirnos, y de manera connotada nos puede servir su idea de analogía, elaborada como hermenéutica analógica, para hacer teología en la actualidad. 
